\title{
Ascensão da extrema-direita na Europa e a questão migratória
}

\author{
Lucas Valente da Costa *
}

Um dos maiores testes a uma União Europeia alargada, nos próximos anos e décadas, será a maneira como gere o desafio da imigração. Se as sociedades europeias estiverem à altura do desafio, a imigração será um fator de enriquecimento e irá fortalecê-las. Se o não conseguirem, isso pode ter como consequência uma descida do nível de vida e a divisão social.

Kofi Annan Artigo no Jornal Público de 29 de Janeiro de 2004

A Europa já esteve melhor ${ }^{1}$. Outrora vista como terra de oportunidades na qual o Estado provê assistência médica, de moradia, educação, desemprego e tantas outras "dádivas" decorrentes do Estado de Bem Estar Social, hoje já não é bem assim. Outrora receptiva aos imigrantes, que eram incentivados a ir ao Velho Continente, pelos mais diversos motivos e, assim, "ganhar a vida", hoje a situação é outra. Outrora ovacionada por causa de sua união econômica e política que tomou a forma mais próxima da atual em 1993, hoje começa a ser questionada e até mesmo surgem dúvidas quanto à sua sobrevivência.

Desde a crise nos Estados Unidos que explodiu em 2008, a União Europeia parece estar sofrendo as maiores consequências. Tentando controlar melhor a

\footnotetext{
* Graduado em Relações Internacionais pela Faculdade de Ciências Sociais/PUC-SP.
} 
situação, que mais chama atenção pelos níveis de desemprego de dois dígitos, o FMI e o Banco Central Europeu impõem medidas similares às aplicadas na América Latina em 1990 com o Consenso de Washington: austeridade fiscal, disciplina orçamentária, aumento de impostos, privatizações, entre outras medidas.

A população não fica impassível a essas mudanças e testemunha-se, hoje, uma série de transformações e manifestações sociopolíticas que têm preocupado muitos especialistas. Essas transformações são o foco deste artigo, em especial aquelas que concernem à questão migratória, ao discurso e à prática do racismo, à xenofobia e certa ascensão da extrema-direita no continente europeu.

Em um primeiro momento, traçamos um panorama dos acontecimentos recentes cujo palco foi a Europa e que tem relação com a crise iniciada em 2008. Em seguida, focamos o discurso daqueles anti-imigração e anti-islâmicos, destrinchando os seus argumentos. Por fim, tecemos uma reflexão teórica sobre a problemática dos imigrantes na Europa.

\section{Europa a Caminho da Direita}

Talvez a expressão mais chocante de certa retomada de força da extremadireita no continente europeu tenha se dado em 22 de julho de 2011. Neste dia, 68 pessoas foram mortas em uma ilha da Noruega, apenas 15 vezes maior que um campo de futebol, a ilha de Utoya, e houve uma explosão em frente a prédios governamentais no centro de Oslo que matou outras 9. Na ilha estava acontecendo um acampamento de jovens, organizado pelo Partido Trabalhista Norueguês, cujo líder é o Primeiro-Ministro do país, no poder desde 2005. 0 responsável pelos ataques, um cidadão norueguês de 32 anos, é declaradamente de extrema-direita e tem ideias islamofóbicas, racistas e de um conservadorismo cultural exacerbado, dizendo que o que está acontecendo hoje na Europa e na Noruega (que não faz parte da União Europeia) é um marxismo cultural.

Este ataque, o pior desde os atentados ao metrô de Londres em julho de 2005, que deixou 52 mortos, não pode ser visto isoladamente ou simplesmente como uma ação individual de um desequilibrado. Ele chama atenção por ter sido realizado por um cidadão do próprio país e cuja motivação foi claramente contrária ao liberalismo e abertura cultural da Noruega. Praticamente todos os outros atentados recentes na Europa, aí incluído o atentado de Madrid em 2004, o mais mortal da Europa, com 191 mortos, foram causados por militantes de grupos terroristas estrangeiros, com uma motivação mais de política externa que interna, quer dizer, movimentos contrários ao envolvimento de países ocidentais em determinados conflitos da Ásia e Oriente Médio.

Estes fatos poderiam até ser interpretados como manifestações de um extremismo isolado, mas o que dizer do resultado das últimas eleições presidenciais francesas? Em junho de 2012, o partido de extrema-direita Front National (FN), encabeçado por Marine Le Pen, obteve seu recorde histórico de votos, com $17,9 \%$ dos sufrágios, ou seja, 6,4 milhões de votos. 
Marine Le Pen, filha do fundador do partido, Jean-Marie Le Pen, tem um discurso abertamente anti-imigração, prega o retorno à pena de morte, disse em 2010 que a oração dos muçulmanos nas ruas é equivalente à ocupação nazista e tem um projeto de lei, atualmente, como eurodeputada, de banir o uso de véus muçulmanos e do quipá judeu nas ruas da França. O partido e seus membros são constantemente envoltos em declarações polêmicas, muitas vezes de tom fascista, chegando mesmo à condenação de alguns de seus membros por negação ao Holocausto, o que é considerado crime não só na França, mas em diversos países da União Europeia.

Mesmo com a derrota de Le Pen no primeiro turno, além do recorde de votos, a eleição de François Hollande, do Partido Socialista (PS), não se deu de maneira tranquila, sendo eleito no segundo turno apenas por uma margem de 3,28\% dos votos, vencendo Nicolas Sarkozy, do Union pour un Mouvement Populaire (UMP), partido de direita.

O resultado destas eleições preocupa muitos países europeus porque é um reflexo do que está pensando a população, daí tal discurso. Relembremos um caso marcante na história mundial cujas consequências todos conhecemos: o Partido Nazista recebeu em 1930, ou seja, pouco depois do crash da Bolsa de Nova York, $18,3 \%$ dos votos nas eleições federais na Alemanha. Em números absolutos foram 6,4 milhões de votos, percentagem e números absolutos, coincidentemente, muito parecidos com os resultados nas eleições federais de 2012 na França, em relação ao Front National. Menos de três anos depois dessas eleições de 1930 , Hitler recebeu $44 \%$ dos votos, foi eleito chanceler da Alemanha e seu partido contou com 850 mil filiados. Esta comparação serve para ilustrar o quão rapidamente um partido pode ascender ao poder, mesmo com um discurso extremista².

Ainda assim, o caso não está restrito apenas à França e ao Front National. Nos Países Baixos, o Partido para a Liberdade (Parti voor Vrijheid), cujo líder Geert Wilder foi banido no Reino Unido por causa de declarações anti-Islã, obteve nas eleições parlamentares de 2010 o terceiro lugar, recebendo 24 (de 150) assentos no Parlamento holandês. Na Alemanha, no mesmo ano, em outubro, foi fundado o Partido da Liberdade (Die Freiheit), ainda pequeno, mas com forte discurso antimuçulmano e revisionista das políticas migratórias e em relação aos estrangeiros. Na Áustria, o Partido Libertário da Áustria (Freiheitliche Partei Österreichs) obteve nas eleições de 2008, 34 assentos no Parlamento, ou $17,5 \%$ dos votos, maior representatividade do partido no Parlamento austríaco desde 1999. Na Itália, desde 1994 que a Lega Nord não obtinha tantos assentos no parlamento como obteve em 2009, partido este que é acusado de xenofobia por causa de suas políticas anti-imigração. Um dos casos mais recentes foi o da lei que entrou em vigor em julho de 2009 e, inter alia, tornou a imigração não documentada passível de multa de até dez mil euros e aumentou o tempo de detenção antes da deportação de três para seis meses. Pior, como a lei criminaliza a imigração e funcionários públicos são obrigados a reportar conduta 
criminal, ela abre espaço para que médicos e professores públicos denunciem seus pacientes e alunos.

$\mathrm{Na}$ Grécia, um dos países mais afetados pela crise, o partido neonazista Aurora Dourada (Chrysi Avgi), com discurso de expulsar todos os imigrantes e fechar as fronteiras com minas terrestres, obteve $7 \%$ dos votos nas eleições de junho de 2012 e garantiu, pela primeira vez, assentos no Parlamento. Chama atenção o símbolo do partido que relembra, e muito, uma suástica. Na Hungria, o terceiro maior partido é o Jobbik, que, defendendo "interesses e valores húngaros" e rechaçando judeus e ciganos, nas eleições de 2010 abocanhou mais de $12 \%$ das cadeiras do Parlamento húngaro, o dobro do que ganhara nas eleições anteriores.

Mesmo na Escandinávia, cujos Estados são os maiores exemplos da política de Bem Estar Social, dificilmente relacionados com a extrema-direita, tem-se visto uma ascensão cada vez maior de partidos com esta bandeira. Na Dinamarca, o Partido Popular da Dinamarca (Dansk Folkeparti) propõe um fim à imigração não ocidental ao país e seu líder, Pia Kjærsgaard, rejeita o multiculturalismo e a multietnicidade, dizendo que seria um desastre para o país. É o terceiro maior partido da Dinamarca e apenas em 2011 igualou o número de assentos que possuía no Parlamento em 2001, 22, tendo chegado em 2007 a 25 assentos (14\% dos votos). Na Noruega, o Partido Progressista (Fremskrittspartiet), que teve como membro e ativista desde jovem, Anders Breivik, autor dos atentados de julho de 2011, tem ideias bem restritivas de imigração e é considerado por especialistas como de extrema-direita. É o segundo maior partido da Noruega e possui o maior número de assentos no Parlamento desde sua fundação em 1973. Vizinho à Noruega, os Democratas Suecos (Sverigedemokraterna), que são o único partido da Suécia a não ter uma política de integração, dizem que são os imigrantes os causadores dos problemas sociais e econômicos no país: receberam pela primeira vez, desde sua fundação em 1988, o direito a vinte cadeiras no Parlamento, por terem atingido nas eleições de 2010, 5,7\% dos votos. Do outro lado do Mar Báltico, o Partido dos Verdadeiros Finlandeses (Perussuomalaiset), tal como o nome indica, de inclinação altamente nacionalista e também eurocéticos, tornou-se o terceiro maior partido da Finlândia, obtendo, em 2011, $19,1 \%$ das cadeiras no Parlamento, ou seja, $15 \%$ mais votos que a maior votação do partido desde sua fundação em 1995.

Em outras instâncias que não as esferas com representação política regulamentada, pululam na internet grupos radicais com causas nacionalistas e integrantes cada vez mais jovens. Segundo estudo feito pela thinktank britânica, divulgado no jornal inglês The Guardian,

os jovens revelam-se cada vez mais críticos para com os seus governantes e União Europeia, estando profundamente preocupados com o futuro e identidade cultural, bem como com o crescimento da imigração e o alastrar da influência 
islâmica na Europa. O estudo adianta que está a crescer na Europa um forte sentimento contra os imigrantes e, especialmente, uma enorme desconfiança em relação aos muçulmanos. Os partidos que difundem ideias xenófobas, anti-imigração e anti-islamitas, estão a espalhar-se para fora dos seus terrenos tradicionais em França, Itália ou Áustria e a conquistar países tradicionalmente mais liberais como a Holanda ou a Escandinávia, tendo agora significativas representações parlamentares nesses países (DN Globo, 7 novembro 2011).

Todos estes países, à exceção da Noruega (mas que faz parte do Espaço Schengen) $)^{3}$, são membros da União Europeia, que tem como um de seus principais discursos o multiculturalismo e que, precisamente, está sendo visto com desconfiança e desaprovação por porções cada vez maiores da população. Neste período de crise, para grande parte das mazelas na Europa, os imigrantes, em especial os não ocidentais, estão servindo de "bode expiatório". "Enquanto o antissemitismo foi um fator de união para partidos de extrema-direita nos anos 1910/20/30, a Islamofobia se tornou o fator de união nas primeiras décadas do século 21", disse Thomas Klau, do Conselho Europeu em Relações Exteriores.

O caso da extrema-direita é o mais evidente, mas mesmo os partidos socialistas estão adotando medidas que sempre foram contrárias às suas diretrizes de base. François Hollande, do Partido Socialista francês, apenas três meses depois de eleito, está dando continuidade às medidas extremamente criticadas de desmantelar acampamentos de imigrantes ciganos. Essas medidas foram iniciadas em 2007 com Nicolas Sarkozy e propõem o retorno de ciganos da Romênia e Bulgária (que são membros da UE, mas não do Espaço Schengen) a seus respectivos países.

Com efeito, a França, junto com a Itália, estão sendo os países com maior peso na UE a proporem mudanças ao Espaço Schengen. Em abril de 2011, Sarkozy parou trens com imigrantes do norte da África que tinham permissão temporária de moradia concedida pelo governo da Itália e que, portanto, poderiam circular livremente pelo Espaço Schengen. Apenas aqueles que puderam comprovar meios de subsistência puderam seguir viagem. A Alemanha adotou medidas iguais. Mais recentemente, em março de 2012, ainda presidente, Sarkozy ameaçou retirar a França da área de livre circulação caso seus vizinhos europeus não adotassem medidas mais duras de imigração.

Já o Reino Unido, que não adotou a moeda única, nem faz parte da área Schengen, ameaça deixar a União Europeia, o que suscita diferentes interpretações. O premiê britânico David Cameron irá, possivelmente, lançar um referendo popular questionando a permanência do país no bloco. Entretanto, existem controvérsias. Há quem diga que isso seria fatal para o bloco, sendo este o primeiro passo para seu desmantelamento, como há também quem diga que seria algo positivo, pois assim o bloco não contaria com as constantes objeções dos britânicos abrindo o caminho para uma possível federalização da 
União Europeia. Tanto uma como outra visão indicam mudanças no bloco, cujas primeiras faíscas se deram em 2008 e agora se agravam nos diferentes campos: econômico, político, social e cultural.

\section{Crise e Extremismo}

O que está se presenciando na Europa não é novidade. Como já mencionado acima, mutatis mutandis, pode-se fazer um paralelo com a ascensão do nazismo após a crise de 1929. No entanto, sabe-se das diferenças históricas também, afinal, a Europa está em relativa paz há mais de seis décadas, enquanto a fundação do Partido Nazista se deu pouco depois da Primeira Guerra Mundial. Ainda assim, surpreende a rapidez com que este ganhou força e, paralelamente, a rapidez com que ganham apoio popular os discursos racistas e xenofóbicos. Diferentemente de outros períodos, agora o poder de mobilização, com as novas tecnologias, via redes sociais e sites de ódio, atinge muito mais gente e de maneira muito mais rápida.

O que está mais presente nos discursos atuais é o nacionalismo como reflexo de um medo de perda de identidade cultural, que estaria sendo posta em risco pela hetero-homogeneização da Europa onde há, respeitando-se cada caso individualmente, cada vez mais uma oferta de mercadorias, um maior fluxo de pessoas de diferentes religiões e etnias, a moeda única, etc. O que acontece, segundo Andrioli (2009, p.1), é que

[...] em períodos marcados pela recessão e pela ausência de movimentos e utopias revolucionárias, abre-se o espaço para a interpretação simplista e populista da realidade, que culpa os estrangeiros pelos problemas sociais. A ausência de alternativas políticas e o consequente sentimento de impotência e desesperança social são um terreno fértil para o aumento da xenofobia.

Paulo Fagundes Vizentini, da UFRGS, escreve sobre os anos 1980, quando houve uma expansão notória de extremistas de direita via skinheads e hooligans, sobretudo na Inglaterra, com tamanha similaridade com o presente que surpreende:

É uma época que vai caracterizar-se pelo desemprego e por incertezas de toda ordem, por desencanto. A população europeia começa a ver sua noção de progresso, prosperidade e segurança ser perdida. Porém, não se fala sobre o tema, não é explicitada a inquietação, mas ao colocar certas questões com inteligência, os europeus demonstram ter medo do futuro. Ou seja, a incerteza com os acontecimentos que estão por vir ou a garantia de emprego. De repente, o emprego passa a ser uma 
virtualidade ou passam a ser frágeis, sem seguro social (VIZENTINI, 2000, p. 2).

Muitos dos discursos são os mesmos, de que os imigrantes irão roubar seus empregos e tentar impor seus modos de vida, que são a causa de todos os problemas de criminalidade e desemprego. São eles, tal como visto hoje, o bode expiatório, alimentado por um discurso cada vez mais racista e xenófobo. Tal como hoje, no início dos anos 1980 a Europa passava por uma grave crise econômica, decorrente das crises petrolíferas dos anos 1973 e 1979, que elevou as taxas de desemprego principalmente entre os jovens, muitas empresas faliram e houve aumento da inflação. A analogia é pertinente, não estaria a história se repetindo, tal como hoje, tal como nos anos 1930 ?

Parece, portanto, haver certa relação entre períodos de crise econômica, que geram desemprego e uma identificação com o discurso de extrema-direita. O que se constata hoje em dia é a existência de toda uma geração perdida. São jovens na faixa dos vinte anos que estudaram mais que seus pais, falam outros idiomas, sabem lidar com novas tecnologias, mas que não conseguem se inserir no mercado de trabalho. Na Espanha e na Grécia, por exemplo, os níveis de desemprego de jovens até os 24 anos beiram os 50\%; em Portugal, Irlanda e Itália, $30 \%$ e na França e Grã-Bretanha já ultrapassaram os $20 \%$. Para piorar, os pacotes de austeridade que estão sendo impostos aumentam a carga tributária e implicam numa menor assistência do Estado aos desempregados, algo que esta geração não chegou a vivenciar. Exagerando, uma parte desses jovens emigra e tenta emprego no exterior; poucos resistem e protestam; outra parte se identifica e se reconforta com o discurso de extrema-direita.

Este é um ponto de vista, mas não o único, pois se verifica que a crise econômica em si não é um fator determinante de ascensão da extrema-direita, como a chegada ao segundo turno nas eleições presidenciais de 2002 de JeanMarie Le Pen. Em 2002 a Europa estava longe de qualquer crise, com a entrada em circulação do Euro em doze países. Apesar de derrotado por uma grande margem pelo candidato à reeleição da UMP Jacques Chirac, foi uma grande vitória para o Front National. Sendo assim, os partidos de extrema-direita apenas ganham força em épocas de crise como alternativa mais atraente para os jovens legitimadores do status quo, jovens esses que não se identificam necessariamente com o antigo conservadorismo nazista findo em 1945. Para eles esse trauma já foi superado. Cecilia Malmström, Comissária da Comissão Europeia para Assuntos Internos resume bem a ideia: "Eu lamento que a crise atual esteja sendo usada por partidos populistas tentando mudar a culpa de economias nacionais mal gerenciadas para populações imigrantes" (tradução nossa) ${ }^{4}$.

Outra consequência da crise é o ganho de motivação e meios políticos, nessa onda nacionalista, de regiões que clamam por sua independência, como é o caso do País Basco, Galícia e Catalunha na Espanha; de Flandres na Bélgica; da Escócia no Reino Unido e da Padânia na Itália. A maioria destas regiões é rica e tem uma 
identidade cultural ou mesmo idioma diferente do resto de seu respectivo país. Aproveitam a crise do euro e da União Europeia para pôr em prática desejos antigos de independência, retomando o conceito fechado de um Estado, de uma nação. No País Basco, por exemplo, em recentes eleições regionais, foi vencedor o Partido Nacionalista Basco, conservador, e em segundo lugar o partido também separatista, mas de esquerda, Euskal Herria Bildu. Possivelmente irão formar uma coalizão para, a exemplo do que será feito na Catalunha, realizar um referendo sobre a separação da região do resto da Espanha.

Após todo o exposto acima, parece que a decisão de premiar a União Europeia em 2012 com o Prêmio Nobel da Paz, cuja premiação se dá em Oslo, Noruega, país que rejeitou por duas vezes sua adesão à UE, é uma tentativa de manter unido este bloco cada vez menos europeísta. Afinal, por que dar este prêmio apenas agora, em uma época de ascensão de movimentos de extremadireita, separatismos e políticas xenofóbicas? A justificativa do prêmio, portanto, já coube melhor à União Europeia: "Por mais de seis décadas contribuindo para o avanço da paz e da reconciliação, democracia e direitos humanos na Europa" (THE NOBEL PRIZE, 2012, tradução nossa).

Um dos temas que mais se destaca no discurso dos partidos de extremadireita é aquele relacionado aos imigrantes. Além das preocupações econômicas, estes partidos pregam, acima de tudo, valores ditos nacionais, anti-imigrantes, e têm o objetivo de preservar a nação e a cultura grega para os gregos, francesa para os franceses e assim por diante. Como a mais recente imigração vem de países muçulmanos, são os muçulmanos, via de regra, os "culpados". Com esse medo, o termo islamofobia se espalhou pela Europa. Impossível não comparar esse "medo crescente" atual na Europa, do "medo vermelho" nos Estados Unidos e no mundo durante a Guerra Fria.

Percebe-se que no cenário, já aqui caracterizado, os partidos de extremadireita estão tendo resultados expressivos nas eleições parlamentares na Europa, pois estão se aproveitando de um momento de fragilidade econômica e social no continente, criando um bode expiatório simples e facilmente identificável - o muçulmano, o imigrante - e, com um discurso populista, incitando as pessoas a rechaçar esta população em nome dos valores e cultura ditos nacionais. $\mathrm{Na}$ Grécia, por exemplo, o Aurora Dourada, à primeira vista, num gesto de boa ação, distribuiu alimentos nas ruas de Atenas; no entanto, apenas alimentos fabricados em solo grego e para cidadãos gregos.

Matthew Goodwin, especialista em extrema-direita da Universidade de Nottingham, diz que preocupações sobre cultura nacional, identidade e estilo de vida importam mais que questões materiais, razão pela qual surgem partidos xenofóbicos tanto em países que estão passando relativamente bem pela crise, como a Holanda, como em outros que estão quase falidos, como a Grécia (GOODWIN, 2012). Ou seja, a questão da crise do euro, em si, pode ser apenas uma coincidência que os partidos estão usando para se erguerem nacionalmente, mas não é necessariamente um fator determinante para o 
surgimento de partidos de extrema-direita (BARLETT, 2011).

Mas afinal, qual a influência dos imigrantes, sejam eles seguidores do Islã ou não, na economia e na cultura "pura" de determinado país? Há uma racionalidade nos argumentos conservadores que estão ganhando cada vez mais simpatizantes, ou é apenas um argumento facilmente "comprável"? O ex-presidente Lula, em discurso em Genebra em frente ao Conselho de Direitos Humanos da ONU, em junho de 2009, ressalta que não se pode culpar os imigrantes pelo que está passando a Europa:

Não são os imigrantes, os pobres do mundo, os responsáveis pela crise. Os responsáveis pela crise são os mesmos que por muito tempo sabiam como ensinar a administrar os Estados. Sabiam como ter ingerência nos Estados pobres da América Latina e da África. [...] esses mesmos senhores que sabiam de tudo um tempo atrás, hoje não sabem mais de nada. Não conseguem explicar como davam tantos palpites nas políticas dos países pobres e que não têm sequer uma palavra para analisar a crise dos países ricos. [...] A crise financeira, que nasceu da desregularização (sic) das economias mais ricas, não será pretexto para incentivar o descumprimento das obrigações de cada Estado com a promoção e proteção dos direitos humanos. Tampouco deve conduzir a que sejam descumpridos compromissos com os mais necessitados (LULA DA SILVA, 2009).

\section{A Questão Migratória Europeia}

Difícil de entender para os partidários da extrema-direita é que a história se faz de imigrantes. Países inteiros se constroem com a participação dos imigrantes. A maior potência do globo, atualmente, é o país que mais recebeu imigrantes na história. Majoritariamente ingleses, mas também irlandeses, poloneses, africanos e latinos construíram e fazem o que os Estados Unidos são hoje. No Brasil é raro encontrar alguém que não diga (e sem qualquer tipo de vergonha) "meu avô era italiano", "minha bisavó era alemã", passando por dezenas de outros países, com destaque para africanos, portugueses, espanhóis, holandeses, japoneses, coreanos e libaneses.

A Europa tem uma história complexa de fluxos migratórios. Dada toda a história migratória do continente, traçamos aqui, de maneira breve e simplificada, um panorama desses fluxos a partir do fim da Segunda Guerra Mundial, período desde o qual existe paz no continente, comparativamente com todo o período anterior ao conflito que terminou em 1945. Assim, espera-se entender melhor a presença dos imigrantes na Europa e o porquê incomodam a uma crescente parte dos europeus.

A origem da questão atual dos imigrantes na Europa, em geral, teve início neste período devido a uma escassez de mão de obra causada, primeiro, pelo 
óbvio motivo das mortes que o conflito gerou, estimadas em cerca de 30 milhões de pessoas somente na Europa. Em segundo lugar, pela necessidade de se reerguerem países inteiros.

Para tanto, muito governos iniciaram programas de "convidar" trabalhadores imigrantes como mão de obra. Alguns países diziam preferir trabalhadores do sul da Europa ou da Europa do Leste, por acreditarem que eles se adaptariam melhor. No entanto, esta mão de obra se mostrou insuficiente e outros países foram considerados, como Turquia e os países do norte da África. Para as ex-potências colonizadoras, como Reino Unido e França, países colonizados como a Índia, Paquistão, Argélia, Marrocos e Tunísia, respectivamente, foram os primeiros países onde seus emigrantes eram incentivados a ir, em decorrência do processo de descolonização. Isso cria uma situação delicada para todos os envolvidos e a Argélia pode ser tomada como exemplo emblemático, pois até 1962 seus cidadãos eram plenamente franceses, lutavam no mesmo exército e podiam ir à França metropolitana quando bem entendessem, o que muda com sua independência e com as então impostas políticas migratórias francesas. No Reino Unido, um imigrante tinha todos os direitos sociais, políticos e econômicos assegurados e, de maneira geral, os imigrantes conseguiam entrar fácil e legalmente, independentemente se isso agradava a população local ou não; grande parte da população não via com bons olhos essa chegada em massa de imigrantes não brancos, mas havia a esperança de que esse fluxo fosse apenas temporário.

Eram necessários enquanto a economia os demandava. Muitos governos, e a população em geral, pensavam que, uma vez a economia voltasse ao normal, esses imigrantes voltariam a seus países. Isso claramente não aconteceu e, como consequência, praticamente todos os países europeus impuseram políticas restritivas à imigração no início da década de 1970. Reino Unido em 1971, França e Alemanha em 1972 e 1973 e todos os outros com uma margem de um ou dois anos de diferença (HANSEN, 2003).

Acontece que esses imigrantes se tornaram cidadãos e, mesmo com as medidas restritivas, clamavam por políticas de reunificação familiar. Com isso, as esposas, filhos e até pais daqueles jovens imigrantes chegavam a ser admitidos. Por apresentarem uma taxa de fecundidade mais elevada que a do europeu nativo - no início de 1980 os cidadãos e residentes permanentes não brancos já eram cerca de $10 \%$ da população total - o assunto não mais escapava dos debates políticos nacionais. Ainda nos anos 1980, os países mais pobres da Europa Portugal, Espanha, Itália, Grécia e Irlanda - que antes eram fornecedores de mão de obra, passam a ser receptores de imigrantes, por apresentarem uma melhoria das condições de vida de seus habitantes.

Nos anos 1990, com o fim da União Soviética e com o Muro de Berlim já no chão, a onda de imigração perde um pouco de seu fulgor e muda de perfil. Os pedidos de asilo de cidadãos da Europa do Leste e da ex-União Soviética, agora 
sem o controle rígido do governo e com as viagens internacionais cada vez mais acessíveis, aumentam. De 1989 a 1992 o número de pedidos de asilo passou de 320 mil para 695 mil, caindo para um número, ainda elevado, de 455 mil no final da década (HANSEN, 2003).

Convém ressaltar que em 1985 foram assinados os acordos de Schengen, que permitem a livre circulação de pessoas entre os países signatários. Atualmente, é um espaço que compreende 26 países. Por conta disso, uma política diretiva comum de imigração e asilo passa a ser cada vez mais necessária, pois um imigrante que consegue o direito de viver permanentemente em Paris, por exemplo, pode se mudar tranquilamente para Madrid, Roma ou mesmo Reikjavik. Sendo assim, desde 1997, com o tratado de Amsterdã e, mais enfaticamente, entre 1999 e 2005, foram adotadas diversas medidas harmonizando padrões mínimos comuns para o fornecimento de asilo.

Atualmente, o Programa Geral "Solidariedade e Gerenciamento de Fluxos Migratórios" dispõe de quase seis bilhões de euros para garantir a divisão justa de responsabilidades entre países da UE para o peso financeiro que provém do gerenciamento integrado das fronteiras externas do bloco e da implementação de políticas comuns de asilo e imigração (MINISTÉRIO DA ADMINISTRAÇÃO INTERNA DE PORTUGAL, 2008). Os quatro principais instrumentos do programa são o Fundo de Fronteiras Externas (EBF), que trata da infraestrutura e equipamentos das fronteiras externas; o Fundo Europeu de Retorno (RF), que gerencia operações de retorno forçado e voluntário, incluindo assistência à reintegração no país de retorno; Fundo Europeu de Refugiados (ERF), para a construção de capacidades, integração de refugiados, reassentamento e medidas de emergência; e o Fundo Europeu para a Integração de Nacionais de Terceiros Países (EIF), com provisão de medidas de integração como cursos de línguas e orientação cívica. Estes seis bilhões de euros divididos entre estes quatro instrumentos são válidos para o período de 2007 a 2013 e são aplicados por meio de programas nacionais de acordo com as necessidades de cada país.

Segundo a Frontex, a Agência Europeia para o Gerenciamento de Cooperação Operacional nas Fronteiras Externas dos Estados Membros da União Europeia, em 2011 entraram irregularmente na Europa, cruzando fronteiras terrestres ou marítimas, com a ajuda de "coiotes", 140.978 pessoas, via sete "portões" principais: Ilhas Canárias, Mediterrâneo oeste, central e leste, Bálcãs, Leste, Rota circular entre Albânia e Grécia, sendo o mais movimentado deles o Central Mediterrâneo. Cecilia Malmström (2012), a Comissária para Assuntos Internos na Comissão Europeia, disse que este tipo de tráfico em direção à Europa se tornou uma indústria que movimenta 25 bilhões de euros por ano. Apesar dos números elevados, ainda é menos da metade dos cerca de 351.000 imigrantes que em 2011 entraram na Europa por aeroportos internacionais, com documentos de viagem válidos e visto, porém, que estenderam seu período de validade e passaram a viver em situação irregular. 
Recentemente, a Primavera Árabe e seus conflitos decorrentes, como o caso atual na Síria, geraram um novo fluxo de imigrantes e de pedidos de asilo no continente. Em 2011, as principais nacionalidades registradas tentando entrar irregularmente, cruzando fronteiras marítimas ou terrestres, em ordem decrescente, foram: Tunísia, Afeganistão, Paquistão, Nigéria, Bangladesh, Argélia, Sérvia, Marrocos, Costa do Marfim, Moldávia, Geórgia, Somália, Guiné e Senegal.

O capítulo recente mais chocante desta história é a construção em curso de um muro de três metros de altura na fronteira terrestre entre Turquia e Grécia. Inicialmente tendo $12,5 \mathrm{~km}$, em construção próximo à cidade turca de Edirne, onde ocorrem $70 \%$ das travessias terrestres entre os dois países, contará com $120 \mathrm{~km}$ de extensão. Sua construção se dá pela polícia grega junto com a Frontex e tem o objetivo de frear a entrada de imigrantes irregulares, vistos com preocupação pelas autoridades gregas. O ministro grego da Ordem Pública, Nikos Dendias, disse que a entrada de imigrantes irregulares levou a Grécia à beira do colapso e que "o país está sendo perdido; o que está acontecendo agora é a maior invasão de todas. Desde a invasão Dórica cerca de 3 mil anos atrás ${ }^{5}$, o país nunca recebeu um fluxo tão grande de imigração" (tradução nossa) ${ }^{6}$. Em 2010, cerca de 36 mil irregulares foram presos na região e levados a centros de detenção, cujas condições são extremamente críticas, com superlotação, acesso limitado ao banheiro e pouca comida.

\section{Enfim, Eles}

Até o momento, este artigo ateve-se à ascensão dos partidos de extremadireita na Europa, trazendo breve histórico daqueles que mais são atacados por estes partidos, apontando quantos são e de onde vêm os imigrantes. Todavia, a pergunta permanece. Qual é, de fato, o impacto econômico e cultural desses imigrantes nas populações autóctones europeias? São tão danosos quanto declaram os nacionalistas de direita?

Há diferentes respostas a estas perguntas, variando muito de acordo com o tipo de análise feita e, evidentemente, das intenções políticas e ideologias existentes por trás das mesmas. É impossível imaginar como se comportaria a sociedade e a economia sem esses imigrantes. As análises sempre se baseiam em modelos econômicos hipotéticos, com a inserção de diversas variáveis que mudam conforme a conjuntura. Além disso, são poucos os estudos europeus sobre o tema, sendo mais abundantes nos Estados Unidos e, relativamente, no Reino Unido. No entanto, o aspecto cultural pode ser mais concretamente observado e, por este motivo, será tratado antes para, em seguida, entrarmos na discussão do impacto econômico da imigração.

Um dos efeitos da imigração mais à vista de todos é aquele relacionado à cultura culinária, ou seja, à alimentação. Hoje em dia é até mesmo difícil imaginar as grandes cidades europeias sem seus kebabs, falafels, restaurantes chineses, indianos, tibetanos e lojas de conveniência abertas até tarde. Movimento 
não exclusivo à Europa, é, possivelmente, uma das consequências mais (gastronomicamente) enriquecedoras da globalização e do multiculturalismo, quando há de fato uma transposição de fronteiras de produtos e hábitos alimentares nacionais. Surpreendentemente, há uma falta enorme de literatura e dados relativos a esta questão (COMISSÃO EUROPEIA, 2006).

Igualmente evidente, mas menos óbvio, é o impacto dos imigrantes no mundo da moda, onde se observa um crescente "exotismo" nos estilos criados pela indústria indumentária. A "moda étnica" já é considerada um segmento estabelecido da indústria têxtil e deriva da adaptação da moda "tradicional", por assim dizer, aos novos costumes trazidos pelos imigrantes e pelo interesse que eles atraem.

Apesar de muitos imigrantes escolherem seus países de destino por causa do idioma comum, fruto da antiga colonização europeia, isso nem sempre é possível. A consequência é o imigrante ou refugiado se deparar em um país no qual ele não domina o idioma e o aprende precariamente por assimilação, sendo raros os casos em que ele pode de fato seguir um curso de idioma. Em julho de 2012 foi publicada uma reportagem no jornal alemão Deutsche Welle em que o linguista da Universidade de Leipzig Uwe Hinrichs (2012) atesta que erros de estrangeiros simplificam o idioma: "ao aprender alemão, é quase inevitável os estrangeiros cometerem erros, pois se trata de um idioma difícil. Com o passar do tempo, os nativos assimilam lentamente esses erros à sua prática de comunicação, e a língua alemã se modifica. Isso afeta, sobretudo, a linguagem coloquial, e não tanto o alemão escrito." Extremamente criticado por "defensores do Santo Graal da língua germânica" como sendo traidor da pátria e favorável ao multiculturalismo da Alemanha, recebeu, em contrapartida, apoio de diversos outros linguistas alemães que confirmaram a fluidez do idioma. Na Alemanha, complementa ele, é normal a ocorrência de um processo chamado code switching, quando imigrantes misturam dois idiomas em sua fala. No caso do alemão, isso se verifica com frequência com o turco, maior grupo imigrante do país, mas, fora o fato disso gerar uma dificuldade a mais de integração de grupos imigrantes à sociedade, não é algo que chegue a incomodar particularmente os cidadãos nativos. Alguns países, tais como Reino Unido, França e a própria Alemanha, para facilitar a integração dos imigrantes à sociedade, fornecem cursos gratuitos de idiomas, porém, apenas para imigrantes documentados, regulares.

Dos aspectos culturais que mais incomodam os nativos, mais que a alimentação, vestimenta (não religiosa) ou o idioma é, sem dúvida, a religião, em especial o Islã. O Islã é tido por conservadores como tendo sido "erradicado" da população nativa europeia, mas está, atualmente, tendo um crescente aumento de seguidores muçulmanos cuja maioria é composta de imigrantes ou filhos de imigrantes. Em um caso recente de evidente islamofobia, o partido conservador suíço, União Democrática do Centro, propôs um referendo popular para a proibição da construção de novos minaretes no país. Com uma população 
muçulmana de 4,3\%, a proibição foi aprovada em novembro de 2009 e suscitou diversos debates da posição da Suíça como islamofóbica, sem, entretanto, gerar mudanças na lei.

Com princípios similares, a França, país da UE com maior número de muçulmanos ${ }^{7}$, proíbe, desde 2004, o uso de símbolos religiosos ostensivos, tais como o véu islâmico ou grandes crucifixos, nas escolas estaduais. Em 2010, entrou em vigor uma lei mais abrangente, que proíbe portar em local público qualquer vestimenta que cubra o rosto, na qual se enquadram cerca de duas mil mulheres que usam a burqa ou o niqab (uma pequena minoria), sendo passível de multa de 150 euros. Tal como na Suíça, a lei gerou protestos e críticas, mas foi mantida. Na Suécia e na Itália já existiam leis equivalentes, de proibição de cobrir o rosto em locais públicos. A justificativa destas leis e sua aprovação é a segurança nacional e a laicidade do Estado, pregada com afinco nas instituições públicas francesas, agora sendo estendida a meios sociais. Nesta linha, tal como dito anteriormente, Marine Le Pen, como deputada, quer ampliar o conceito da lei que restringe objetos religiosos ostensivos nas escolas estatais para todas as esferas públicas, até nas ruas.

Por fim, analisamos, na medida do possível, a partir da perspectiva econômica, o efeito dos imigrantes nos empregos, salários, contas públicas, PIB, etc. Esta apreciação é feita com base em diversos estudos nacionais, dada a falta de um estudo europeu centralizado. O mais próximo disso é a Rede Europeia de Migrações, uma rede coordenada pela Comissão Europeia estabelecida em cada Estado Membro da UE, mais a Noruega, e cujo propósito é fornecer informações atualizadas, objetivas, confiáveis e comparáveis sobre imigração e asilo para, assim, auxiliar nas políticas da União Europeia sobre o tema (JORNAL OFICIAL DA UNIÃO EUROPEIA, 14 de maio de 2008).

Um dos estudos realizados pelo governo britânico em 2005 para avaliar o impacto dos imigrantes na economia se deu por comparação da proporção de imigrantes (nascidos no estrangeiro) no Reino Unido, com a parte do PIB que Ihes concernia. Segundo o estudo, $8 \%$ da população do Reino Unido era imigrante e eles geraram um incremento de $10 \%$ no PIB nacional, sendo assim, contribuindo para a economia do país. Estes resultados foram duramente criticados pela Migration Watch UK, que contestou os dados do governo e disse que eles não incluíram os filhos dos imigrantes nascidos em território britânico que, se considerados, fariam com que, na comparação, os imigrantes teriam um impacto negativo na economia. Sete anos depois, outro órgão do governo britânico, o Migration Advisory Commitee (MAC) atestou em um relatório de 156 páginas, entre outras coisas, que de cada cem imigrantes em idade ativa, provenientes de fora da UE, 23 empregos de nativos britânicos eram perdidos. Ainda outro órgão do governo, o National Institute of Economics and Social Research (NIESR) estimou em um relatório separado e divulgado em janeiro de 2012 que o efeito sobre o PIB per capita do imigrante seria ligeiramente positivo e a imigração teria um impacto mínimo ou nulo no número de desempregados nativos. 
O caso britânico é interessante de se observar, pois ele deixa evidente a dificuldade de se avaliar de fato o impacto do imigrante na economia nacional. As pesquisas são muitas, os resultados divergentes e as críticas incessantes. Danny Shaw, jornalista da BBC, resume bem o porquê desses diferentes resultados e, parcialmente, um dos motivos que está levando a uma maior identificação de parte da população com o discurso anti-imigrante da direita: "Os efeitos da imigração não europeia são mais sentidos em tempos em que a economia vai mal, ou seja, quando há desemprego, e no curto prazo, antes de o mercado de trabalho ter tempo de se ajustar" (SHAW, 2012, tradução nossa) $)^{8}$. Giovani Peri, professor associado da Universidade da Califórnia em Davis e acadêmico visitante do Federal Reserve Bank de São Francisco completa: "Em recessões, no entanto, novos imigrantes são tidos por terem um pequeno impacto negativo nos empregos dos nativos no curto prazo (mas não no longo prazo)" (PERI, 2010a, p. 7, tradução nossa). Ou seja, em períodos nos quais a economia vai bem, os imigrantes não são culpados por estarem roubando o emprego dos nativos já que, afinal, todos estão bem empregados. Mas em épocas de recessão se tem a ideia de que o emprego que um imigrante ocupa poderia estar sendo ocupado por um nativo.

Este argumento é um dos mais propagados pelos anti-imigrantes, tanto na Europa como nos Estados Unidos, porém, há muitos estudos que o provam infundado, pois se limita à lei da oferta e da procura, como se houvesse um número de empregos fixo em uma sociedade e cada emprego ocupado por um imigrante representasse um emprego a menos para um nativo. Giovani Peri, em seu relatório do Migration Policy Institue, de junho de 2010, no qual resume pesquisas recentes sobre a economia da imigração, atesta que os imigrantes têm um efeito positivo sobre os empregos e salários dos nativos e que eles estimulam a economia.

Segundo Peri (2010b), em uma entrevista em outubro a Mark Engler, analista sênior da Foreign Policy in Focus, os imigrantes precisam ser enquadrados, além da lei da oferta e da procura, ao princípio da complementaridade:

Se dois trabalhadores são completamente iguais, a oferta e a procura entram em vigor - da mesma maneira que, se pusermos mais milho no mercado, o seu preço baixa. Mas se tivermos trabalhadores cujos empregos sejam diferentes e se eles se especializarem em tipos de tarefas que são complementares, isto pode aumentar os salários e a produtividade de ambos.

Isso, de fato, pode ser visto tanto nos Estados Unidos como na Europa, aplicando-se, no entanto, apenas aos imigrantes pouco qualificados.

Um exemplo extremo disto seria se tivéssemos um engenheiro e lhe juntássemos um operário da construção 
civil. Só com o engenheiro não íamos conseguir lá muito. Mas com um engenheiro e um operário da construção civil podemos construir um edifício. Consequentemente, a produtividade do engenheiro aumenta muito. E os salários de ambos os trabalhadores aumentam (PERI, 2010b).

No caso de imigrantes altamente qualificados e que estão em uma situação regular - diga-se, uma minoria absoluta dos que chegam todos os anos à União Europeia - o discurso já muda. Este tipo de imigrante pode, sim, ocupar o emprego de um nativo e, assim, em teoria, contribuir para uma maior taxa de desemprego entre os locais. Quem defende isso não é nenhum radical, é um imigrante. Edwin Okongo, um queniano que mora regularmente nos EUA há mais de vinte anos e que passou por todos os trabalhos "típicos de imigrante", como esfregar chão, panelas, banheiros, organizar prateleiras em supermercados, vigiar prédios e estacionamentos, entre outros. Atualmente, no entanto, depois de ter feito faculdade nos EUA, tornou-se professor na Universidade da Califórnia, Berkley, e admite em seu blog no Huffington Post:

Eu sou provavelmente o único imigrante com coragem para admitir que nós somos os culpados pelos altos níveis de desemprego nos EUA. Mas não os imigrantes sem documentos [...]. Acreditem, vocês não querem os empregos que estes imigrantes fazem. São imigrantes legais como eu que vocês deveriam estar culpando pela condição de vocês (OKONGO, 2012, declaração em blog).

Voltando a Peri, ao comentar o trabalho de um dos maiores defensores da redução da imigração nos EUA, George Borjas, da Universidade de Harvard, concorda com ambas as declarações. Borjas diz que a imigração pode ter um efeito negativo de $3 \%$ nos salários dos trabalhadores nativos com educação inferior, mas que entre os trabalhadores com educação superior e intermediária o efeito é, ao contrário, positivo. No entanto, Peri discorda do ponto de vista de Borjas que defende a tese de que os imigrantes não ocupam os postos que os nativos não querem e que, caso os imigrantes não ocupassem esses postos, a economia se rearranjaria para suprir as mesmas posições, seja com o reajustamento de preços em um mercado de trabalho competitivo ou com o crescimento da oferta de trabalho local que resultaria em uma ausência de imigração (BORJAS, 2010). Segundos os estudos de Peri, nativos e imigrantes ocupam realmente empregos diferentes, têm capacidades diferentes e especializam-se em tarefas produtivas diferentes, o que reduz a competitividade direta mesmo em relação aos locais com baixa qualificação (PERI, 2010a).

Outro ponto interessante que merece ser considerado é o envelhecimento da população nativa europeia, junto com baixas taxas de fecundidade. Segundo o Instituto Max Planck, da Alemanha, nenhum país da Europa tem, hoje, o "nível 
de substituição" de 2,1 filhos por mulher, com o qual a geração dos filhos substituía aquela de seus pais ${ }^{9}$. Nos países do sul e do leste europeus a situação é mais grave que a de suas contrapartes do norte e oeste. Na Itália, segundo um estudo de 2002, conduzido por Hans-Peter Kohler, José Antonio Ortega e Francesco Billari, a taxa de fecundidade era de baixíssimos 1,3 filhos por mulher. Nesta taxa, a população do país pode ser diminuída pela metade até $2047^{10}$. Hoje, segundo a ONU, a taxa na Itália encontra-se em 1,38 filhos por mulher. Nestes termos, os imigrantes têm um papel essencial para manter um nível mínimo de pessoas em idade ativa, dado seu influxo aos países em questão e às suas maiores taxas de fecundidade e, assim, manter a economia rodando. Para efeito de comparação, as quatro nacionalidades que mais afluíram à União Europeia em 2011, Tunísia, Afeganistão, Paquistão e Nigéria têm, respectivamente, taxas de fecundidade de 1,9; 7,0; 3,5 e 5, $3^{11}$.

A análise do impacto econômico dos imigrantes pode ser muito extensiva caso sejam considerados todos os custos que concernem a um imigrante irregular, passando pelos gastos que um Estado tem para patrulha de fronteira, deportação, detenção, benefícios sociais que se estendem mesmo aos imigrantes, políticas de integração, entre tantos outros. Da mesma maneira, os ganhos que o Estado receptor tem com o imigrante também podem ser muitos, tendo sido dado destaque para alguns pontos acima, mas que abrangem também a riqueza produzida por eles, o enriquecimento cultural, o dinamismo da economia, entre outros.

\section{Considerações Finais}

O papel do imigrante nos Estados europeus ainda será muito debatido, passando por momentos mais efusivos em épocas de crise econômica (sem, como visto, o imigrante ser "culpado" pela crise). Junto com a crise, como testemunhado pela história, mas não diretamente relacionado, ascendem mais facilmente os partidos de extrema-direita conservadores e com ideias contrárias ao multiculturalismo, passando por um exacerbado discurso nacionalista identitário que compreende até partidos separatistas.

A força que a extrema-direita tem adquirido nos últimos anos na Europa deve ser vista com cautela tanto do ponto de vista da segurança dessa população estrangeira, como da propagação destas ideias, desta mentalidade, cada vez mais autocentrada e unicultural. Não se deve esquecer nunca que Hitler chegou ao poder democraticamente, quando na época se culpava os judeus por todas as mazelas da sociedade alemã, mas que hoje, olhando para trás, se reconhece o peso que o preconceito e ideias "científicas" de raça tiveram nesta política. Políticas extremas contra imigrantes já permeiam os partidos mais radicais sem que os imigrantes sejam os culpados dos problemas sociais e econômicos atuais nas sociedades desenvolvidas.

Acrescenta-se no rol dos não esquecimentos que o discrepante mundo capitalista de hoje está globalizado, com um fluxo internacional de mercadorias 
e serviços, maior do que nunca na história da humanidade, mas com o polêmico fluxo de pessoas barradas por muros. Com isso, antigas ideias fechadas de um mundo de outrora devem ser adaptadas, tal como um idioma que está sempre em constante mudança - foi assim que o Vossa Mercê passou por vossemecê e vosmecê, até virar o atual você, aceito por todos e que foi consagrado pelo uso.

o "outro" assusta, mas não se pode deixar o medo e o preconceito superarem a racionalidade e a solidariedade que nos fazem humanos, mesmo com tantos exemplos quotidianos que parecem tentar borrar o fato que o "outro" é simplesmente um indivíduo que nasceu do outro lado de uma linha criada pelo homem chamada fronteira.

\section{Notas}

1 - Este artigo é resultado do trabalho de conclusão de curso em Relações Internacionais pela Faculdade de Ciências Sociais/PUC-SP. Esclarecemos que não é nossa intenção analisar os resultados dos processos eleitorais nos países da União Europeia, os quais, em muitos casos, alternam no poder ora a direita, ora a esquerda, mas sim o fato de certa ascensão da extremadireita neste momento e sua relação com a questão migratória.

2 - Nesse sentido, ressalta-se a reflexão da Escola de Frankfurt feita por um dos seus fundadores, T. Adorno, no texto em que reflete sobre o holocausto dizendo que só a educação pode prevenir novos holocaustos (ver ADORNO, 1994. p. 33-45). Reflexão esta confirmada por recente estudo da Universidade Livre de Berlim com milhares de estudantes alemães entre 15 e 16 anos, cujo resultado é chocante e ressalta a importância do estudo da História: metade dos estudantes desconhece que Hitler foi um ditador e um terço desses jovens o consideram um defensor dos direitos humanos (NOVAES, 2012).

3 - Compreende os países signatários de acordos firmados em 1985 que permitem a livre circulação de pessoas entre tais países.

4 - Transcrição obtida em entrevista dada por Malmström ao The Wall Street Journal em 15 de setembro de 2012.

5 - O ministro faz referência à invasão dos dóricos, povo das ilhas gregas do sul, entre 1200 e 1100 a.C. que teria culminado no fim da Idade do Bronze grega e da civilização micênica, provocando a destruição de cidades, fuga das populações, declínio artístico e cultural. Este período ficou conhecido na história grega como Idade Obscura ou Idade das Trevas gregas, apenas terminando em meados do século VIII a.C. quando as cidades-estado voltam a crescer, com o desenvolvimento da escrita alfabética grega, a criação dos poemas de Homero e das Olimpíadas.

6 - Declaração do Ministro Dendias publicada no The Independent em 7 de agosto de 2012.

7 - Apesar de ser proibido por lei a pesquisa religiosa, o número de muçulmanos na França é estimado entre $5 \%$ e $10 \%$ da população, o que pode equivaler a aproximadamente 6 milhões de pessoas (Le Figaro, 07/04/2011).

8 - Análise do correspondente de assuntos domésticos da BBC News, Danny Shaw, em resposta à reportagem do mesmo veículo "Immigration from outside the EU 'linked to UK jobless'", de 10 de janeiro de 2012.

9 - Dados do estudo do Instituto Max Planck, obtidos em reportagem de 12 jan. 2009 do Deutsche Welle.

10 - Previsão dos pesquisadores Hans-Peter Kohler, José Antonio Ortega e Francesco Billari, de 2002, obtidos em reportagem de Russell Shorto, do The New York Times de 29 jun. 2008.

11 - United Nations World Population Prospects, the 2010 revision. 


\section{Referências}

ADORNO, T. W. Educação após Auschwitz. In: COHN, G. (org.) Theodor W. Adorno. São Paulo: Editora Ática, 1994. p. 33-45.

ANDRIOLI, A. O neonazismo ronda a Europa. Revista Espaço Acadêmico, no 97, v. 9, p. 1, junho 2009. Disponível em: <http://periodicos.uem.br/ojs/index.php/EspacoAcademico/ article/viewFile/7170/4133>. Acesso em: 7 nov. 2012.

BARLETT, J. Estudo da Thinktank Demos In: DN Globo, 7 nov. 2011. Disponível em: <http:// www.dn.pt/inicio/globo/interior.aspx?content_id=2105764>. Acesso em : 20 feb. 2013.

BORJAS, G. In: TRIBALAT, M. Les Yeux grands fermés: L'immigration en France. Lonrai: Denoël, 2010.

COMISSÃO EUROPEIA. European Migration Network. Impact of Immigration on Europe's Societies. Luxemburgo: Office for Official Publications on the European Community, 2006.

GOODWIN, M. Why the eurozone crisis doesn't spell a return to the well of nazism. The Guardian, Londres, 22 mai. 2012. Disponível em: <http://www.guardian.co.uk/ commentisfree/2012/may/22/eurozone-crisis-nazism>. Acesso em: 7 nov. 2012.

HANSEN, R. Migration to Europe since 1945: Its History and its Lessons. The Political Quarterly Publishing. Oxford: Blackwell, 2003. Disponivel em: <http://homes.chass.utoronto. ca/ rhansen/Articles_files/20031.pdf>. Acesso em: 7 nov. 2012.

HINRICHS, U. In: ARNOLD, R. Influência de imigrantes modifica idioma alemão. Deutsche Welle. 28 jul. 2012. Disponível em: <http://www.dw.de/influ\%C3\%AAncia-de-imigrantesmodifica-idioma-alem\%C3\%A3o/a-16128288-1>. Acesso em: 7 nov. 2012.

KLAU, T. In: O Estado de S. Paulo. 29 de abril de 2012. Disponível em: <http://www. estadao.com.br/noticias/impresso,grupos-xenofobos-ja-compoem-nove--governoseuropeus-,866711,0.htm>. Acesso: em 20 fev. 2013.

LULA DA SILVA, L. In: UCHOA, P. BBC Brasil. 15 jun. 2009. Disponível em: <http://www.bbc.co.uk/ portuguese/noticias/2009/06/090615_lulaonupu_ba.shtml>. Acesso em: 20 fev. 2013.

MALMSTRÖM, C. In: STEVIS, M. Illegal Immigration Emerges as New Crisis for Greece - And EU. The Wall Street Journal. Patras, 15 set. 2012. Disponível em : <http://online.wsj.com/article/ SB10000872396390444506004577617383132000476.html>. Acesso em: 7 nov. 2012.

MIGRATION ADVISORY COMMITTEE. Analysis of the Impacts of Migration. Londres: UK Home Office, 2012. Disponível em: <http://www.ukba.homeoffice.gov.uk/sitecontent/ documents/aboutus/workingwithus/mac/27-analysis-migration/01-analysis-report/ analysis-of-the-impacts?view=Binary>. Acesso em: 7 nov. 2012.

MINISTÉRIO DA ADMINISTRAÇÃO INTERNA DE PORTUGAL. Programa-Quadro SOLID. Disponível em: <http://www.fundoscomunitarios.mai.gov.pt/proquadro/Paginas/default. aspx>. Acesso em: 26 fev. 2013.

NOVAES, J. Metade dos Estudantes alemães desconhece que Hitler foi um ditador, revela pesquisa. Opera Mundi, 30 jun. 2012.

OKONGO, E. Blame Legal Immigrants Like Me for Taking Your American Jobs. The Huffington Post, Berkley, Califórnia, 18 jun. 2012. Disponível em: <http://www.huffingtonpost.com/ edwin-okongo/american-jobs-immigrants_b_1606085.html>. Acesso em: 7 nov. 2012.

PERI, G. The Impact of Immigrants in Recession and Economic Expansion. Washington, D.C.: Migration Policy Institute, junho 2010a. Disponível em: <http://www.migrationpolicy.org/ pubs/Peri-June2010.pdf>. Acesso em: 7 nov. 2012.

PERI, G. Imigração tem efeito positivo sobre emprego e salários: entrevista. [5 de outubro, 2010b]. Esquerda.net. Entrevista concedida a Mark Engler. Disponível em: <http://www. esquerda.net/artigo/imigra\%C3\%A7\%C3\%A3o-tem-efeito-positivo-sobre-emprego-esal\%C3\%A1rios>. Acesso em: 7 nov. 2012.

REDE EUROPEIA DE MIGRAÇÕES. In: Jornal Oficial da União Europeia de 14 de maio de 2008. 
Disponível em:<http://eur-lex.europa.eu/LexUriServ/LexUriServ.do?uri=OJ:L:2008:131:0 007:0012:PT:PDF>. Acesso em: 20 fev. 2013.

SHAW, D. Immigration from outside the EU 'linked to UK jobless'. BBC. 10 jan. 2012. Disponível em: <http://www.bbc.co.uk/news/uk-16484918>. Acesso em: 7 nov. 2012.

SHORTO, R. No Babies? The New York Times, 29 jun. 2008. Disponível em: <http://www. nytimes.com/2008/06/29/magazine/29Birth-t.html?pagewanted=all\&_r=1\&>. Acesso em: 7 nov. 2012.

VIZENTINI, P. F. O ressurgimento da extrema-direita e do neonazismo: a dimensão histórica e internacional. In: MILMAN, L. e VIZENTINI, P. (orgs.) Neonazismo, Negacionismo e Extremismo Político. Porto Alegre: Editora da Universidade, 2000. Disponível em: <http:// www.derechos.org/nizkor/brazil/libros/neonazis/cap4.html>. Acesso em: 7 nov. 2012.

THE NOBEL Peace Prize 2012. Nobelprize.org. Disponível em: <http://www.nobelprize.org/ nobel_prizes/peace/laureates/2012/>. Acesso em: 20 fev. 2013.

\title{
RESUMO
}

Os resultados recentes de diversas eleições parlamentares em países europeus chamaram atenção pela quantidade de assentos que conseguiram partidos de extrema-direita com propostas xenofóbicas explícitas, alguns com votações recordes. Neste artigo, através da análise de diversos acontecimentos sociais e políticos e do estudo do impacto dos imigrantes na economia e sociedade europeia, faz-se uma relação entre o apoio popular a esses partidos em períodos de recessão econômica, especialmente aquele iniciado em 2008 , ainda em curso em muitos países do continente europeu, com o impacto real dos imigrantes na estrutura econômico-social. Isto é devido ao corrente discurso de que imigrantes são a causa do desemprego dos nativos, discurso este que precisamente ganha força em períodos em que os empregos estão mais escassos. Os estudos analisados concluem que os imigrantes não contribuem para este fato, mas que tal discurso ganha apoio em períodos de crise, antes que a economia tenha tempo de se adaptar.

Palavras-chave: imigração; extrema-direita; União Europeia.

\begin{abstract}
Recent results of various parliamentarian elections in European countries have brought about attention and concern due to the number of seats taken by far-right parties with explicit xenophobic proposals. The results of some elections are without historic precedent. In this article, through the analysis of a wide range of social and political events and through the study of the impact of immigrants in European economics and society, popular support to these parties in times of economical recession, in particular the one that has begun in 2008 and is still engrossed in many countries of the continent, is linked with the real impact of immigrants on the social-economical structure. This is due to the common speech that immigrants are the cause of unemployment among the local population, a discourse intensifying while employment is scarce. The studies analyzed conclude that immigrants do not give rise to it, but this discourse increases in times of crisis, until the economy will have readjusted itself.
\end{abstract}

Keywords: immigration; far-right; European Union. 